\title{
Qual África ensinar nas escolas? A história africana e afro-brasileira nos Relatórios Finais de Estágio Supervisionado do curso de História da UDESC (2000 - 2006) ${ }^{1}$
}

Maíra Pires Andrade ${ }^{2}$

Resumo: Este artigo investiga quais são as representações sobre a História Africana e Afro-brasileira que são expressas pelos estudantes de Graduação em História da UDESC, na condição de estagiários na Educação Básica, que irão ressoar nos Relatórios Finais da disciplina de Estágio Supervisionado dos anos 2000 até 2006. Nesse sentido, o objetivo é perceber como os estagiários do último ano do Curso de Graduação e os estudantes da Educação Básica dão significado a esta temática. Como aporte teórico usarei principalmente autores como Fanon, Quijano e Mbembe, para pensar a colonialidade e o racismo na atualidade, e Hall, para mobilizar o conceito de representação. Nesse aspecto, irei abordar os trechos dos relatórios em que a África ou as populações negras são invisibilizadas. Irei atentar para a visão eurocêntrica articulada pelos estagiários através das suas categorias e, por final, salientarei os trechos em que estas populações são tratadas como objetos, colocadas no lado oposto da ação humana. Este artigo é um recorte de uma dissertação em desenvolvimento na UDESC que perceberá as rupturas nestes relatórios antes e depois da aprovação da lei 10.639/03, estabelecendo relações entre as apropriações dos estagiários e o que é compreendido pelos estudantes das escolas que são campo de estágio.

Palavras Chave: História Africana e Afro-Brasileira. Representação. Racismo. Lei 10.639/03.

Abstract: This article investigates the representations about African History and Brazilian African that are expressed by the undergraduate students in History of UDESC in the condition of trainees in Basic Education that will resonate in the Final Reports of the discipline of Supervised Internship from

\footnotetext{
${ }^{1}$ Este artigo é um recorte da dissertação de mestrado "Qual África? A história das Áfricas e as práticas de ensino na UDESC (2000-2015)".

${ }^{2}$ Mestranda no Programa de Pós-Graduação em História da Universidade do Estado de Santa Catarina (UDESC) na área de História do Tempo Presente. Graduada em História em 2015 pela UDESC.
} 
the year 2000 to 2006. In this Sense, the objective is to understand how the trainees of the last year of the Undergraduate Course and the students of Basic Education give meaning to this theme. As a theoretical contribution I will mainly use authors such as Fanon, Quijano and Mbembe to think about coloniality and racism in the present and Hall to mobilize the concept of representation. In this regard, I will address the excerpts from the reports in which Africa or Black populations are invisible. I will pay attention to the Eurocentric vision articulated by the trainees through their categories and at the end I will highlight the stretches in which these populations are treated as objects placed on the opposite side of human action. This article is a cut of a dissertation under development in the UDESC that will perceive the ruptures in these reports before and after the approval of Law 10.639 / 03, establishing relations between the appropriations of the trainees and what is understood by the students of the schools that are field of internship .

Keywords: African and Afro-Brazilian History. Representation. Racism. Law $10.639 / 03$.

Este artigo investiga quais são as representações sobre a História Africana e Afro-brasileira que são expressas pelos estudantes do último ano da Graduação em História da UDESC, na condição de estagiários na Educação Básica, que irão ressoar nos Relatórios Finais da disciplina de Estágio Supervisionado dos anos 2000 até 2006. Este trabalho é resultado de um recorte de uma pesquisa de mestrado em desenvolvimento, que tem como eixo temporal 2000 até 2015; contudo, neste recorte irei utilizar como documento somente os Relatórios Finais de 2000 a 2006, contabilizando um total de 10 relatórios, procurando compreender como os estagiários e estudantes se apropriam e entendem o ensino de História das Áfricas.

Segue abaixo um quadro em que se descreve, respectivamente, o título dos relatórios analisados neste artigo, os autores, a escola campo 
de estágio, o bairro em que está localizada, a turma em que as aulas foram aplicadas e o ano de publicação do relatório.

Revista Vernáculo n. ${ }^{\circ} 40$ - segundo semestre /2017

ISSN 2317-4021 
Quadro 1 - Relação de Relatórios de Estágio Analisados de 2000 a 2006

\begin{tabular}{|c|c|c|c|c|}
\hline Título & Autores & Escola/ Bairro & $\begin{array}{l}\text { Ano/ } \\
\text { Nível }\end{array}$ & $\begin{array}{c}\text { Ano de apresentação } \\
\text { do Relatório }\end{array}$ \\
\hline $\begin{array}{l}\text { A música: cantigas } \\
\text { e histórias da ilha }\end{array}$ & $\begin{array}{c}\text { Alexandre Martins } \\
\text { Haroldo Silis Mender da } \\
\text { Silva }\end{array}$ & $\begin{array}{l}\text { Centro Cultural } \\
\text { Escrava Anastácia/ } \\
\text { Mont Serra }\end{array}$ & Não especificado & 2000 \\
\hline Imigração e Colonização & $\begin{array}{c}\text { Cesar Cancian Dalla Rosa } \\
\text { Mário Ernesto Kuhne } \\
\text { Leda Maria Fernandes }\end{array}$ & $\begin{array}{l}\text { Colégio de } \\
\text { Aplicação/ Trindade }\end{array}$ & $1^{\circ}$ ano Ensino Médio & 2001 \\
\hline Relatório de Estágio & $\begin{array}{c}\text { Evilasia Poluceno } \\
\text { Marlen Batista de Martino } \\
\text { Milana Cristina Lazzaris }\end{array}$ & $\begin{array}{l}\text { Colégio de } \\
\text { Aplicação/ } \\
\text { Trindade }\end{array}$ & $1^{\circ}$ ano Ensino Médio & 2001 \\
\hline $\begin{array}{l}\text { Violência hoje e suas raízes } \\
\text { sociais no período colonial }\end{array}$ & $\begin{array}{c}\text { Marcia Claudio Cardoso da } \\
\text { Silva } \\
\text { Marcos Anderson Tedesco } \\
\text { Thiago Juliano Sayao }\end{array}$ & $\begin{array}{l}\text { Escola de Educação } \\
\text { Básica Simão } \\
\text { Hess/Trindade }\end{array}$ & $2^{\circ}$ ano Ensino Médio & 2001 \\
\hline À ditadura, aquele abraço & $\begin{array}{c}\text { Ana Carolina Wessler } \\
\text { Prudêncio da Silva } \\
\text { Ana Laura Tridapalli } \\
\text { Roberto Oliveira do Prado }\end{array}$ & $\begin{array}{l}\text { Escola Anisio } \\
\text { Teixeira/ Costeira }\end{array}$ & $3^{\circ}$ ano Ensino Médio & 2005 \\
\hline $\begin{array}{l}\text { A revolução industrial e a } \\
\text { inserção de Florianópolis na } \\
\text { modernidade }\end{array}$ & $\begin{array}{c}\text { Elisângela da Silva Landra } \\
\text { Joel Spcart } \\
\text { José Rada Neto }\end{array}$ & $\begin{array}{l}\text { Escola Anisio } \\
\text { Teixeira/Costeira }\end{array}$ & $2^{\circ}$ ano Ensino Médio & 2005 \\
\hline $\begin{array}{c}\text { As experiências da } \\
\text { docência: novas } \\
\text { perspectivas sobre o ensino }\end{array}$ & $\begin{array}{c}\text { Israel da Silveira } \\
\text { Kelwyn Pfleger } \\
\text { Sávio Lopes Pavanello }\end{array}$ & IEE / Centro & $2^{\circ}$ ano Ensino Médio & 2006 \\
\hline
\end{tabular}

Revista Vernáculo n. ${ }^{\circ} 40$ - segundo semestre /2017

ISSN 2317-4021 


\begin{tabular}{|c|c|c|c|c|}
\hline de história & & & & \\
\hline $\begin{array}{c}\text { A guerra fria e a ditadura } \\
\text { militar no Brasil: Em busca } \\
\text { de uma história em } \\
\text { movimento }\end{array}$ & $\begin{array}{l}\text { Mateus Perez Jorge } \\
\text { Maro Schweder } \\
\text { Fábio Macedo }\end{array}$ & IEE/Centro & $2^{\circ}$ ano Ensino Médio & 2006 \\
\hline $\begin{array}{c}\text { Escravos, alemães, } \\
\text { subversivos na Ditadura e } \\
\text { moradores de favela durante } \\
\text { os séculos XIX e XX da } \\
\text { história do Brasil e de Santa } \\
\text { Catarina }\end{array}$ & $\begin{array}{c}\text { Ademir Soares Luciano } \\
\text { Junior } \\
\text { Cíntia Ertel Silva }\end{array}$ & IEE/ Centro & $1^{\circ}$ ano Ensino Médio & 2006 \\
\hline $\begin{array}{c}\text { República em Santa } \\
\text { Catarina: modernidade e } \\
\text { exclusão - ações e reações } \\
\text { que transformaram as } \\
\text { estruturas sociais, políticas } \\
\text { e econômicas entre o fim do } \\
\text { século XIX e início do } \\
\text { século XX }\end{array}$ & $\begin{array}{c}\text { Alecsandro Diehl } \\
\text { Claudete Maria Guedes } \\
\text { Janete Maria Pasini }\end{array}$ & IEE/Centro & $1^{\circ}$ ano Ensino Médio & 2006 \\
\hline
\end{tabular}

Fonte: Elaborado pela autora, 2016.

Revista Vernáculo n. ${ }^{\circ} 40$ - segundo semestre /2017

ISSN 2317-4021 


\section{O mundo não é o que existe, mas o que acontece ${ }^{1}$}

Da História a ser ensinada ao que é ensinado, nesse caso, a temática das Áfricas, é preciso pensar por que esta comumente não é selecionada para ser ensinada. Para isso, em consonância com as contribuições da tese de doutoramento de Luiz Fernandes de Oliveira (2010), tomarei como perspectiva o entendimento de que os desafios enfrentados pelo ensino de História das Áfricas, assim como as representações estereotipadas acerca desta, são resultados da herança da ação de empreendimentos coloniais que se instalaram sobre 0 continente africano colonizando o poder, o saber e o ser, permanecendo seus resquícios ainda na atualidade. Para este autor, a inserção das sociedades africanas na modernidade, assim como também de outras populações que foram subalternizadas, como a América Latina e a Ásia, é pautada pelo processo de colonialidade, no qual, para além das relações políticas e econômicas advindas do colonialismo, permanecem imersas na colonialidade do poder, do saber e do ser, em outros termos podemos falar do racismo que surge como estrutural em nossa sociedade. Dito de outro modo, estou querendo evidenciar que o capitalismo, ao adentrar nessas populações, irá impor um padrão de poder sustentado na dominação colonial; este padrão é o que Quijano (2009) chama de colonialidade do poder, que se refere aos diversos instrumentos de controle de subjetividade, exploração do trabalho e

\footnotetext{
${ }^{1}$ Dito de Tizangara retirado da obra do escritor moçambicano Mia Couto (2005) "O último vôo do flamingo".
} 
hierarquização do mundo; conforme Fanon (2005), este padrão será a expressão do racismo que irá discriminar os modos de ser e estar no mundo de todos os negros.

Nesse horizonte, a instituição escolar, como um elemento da modernidade, com todos os seus mecanismos disciplinadores, corrobora, também, para o controle das subjetividades e do conhecimento, sendo partícipe do projeto colonizador e da modernidade. A disciplina de História, seguindo esta mesma lógica, surgirá como uma narrativa necessária para a constituição das nações europeias, os chamados Estados Nacionais, conformando uma narrativa que irá condicionar os corpos, saberes, valores e conteúdos indispensáveis para a nação desejada nos moldes civilizatórios, e é nesta ponderação que se localiza a resposta à questão feita no início deste subitem.

O primeiro Relatório Final de estágio a ser descrito e analisado é intitulado "A música: cantigas e histórias da ilha"; foi publicado no ano 2000, sendo referente ao grupo de estagiários que atuou no Centro Cultural Escrava Anastácia na Comunidade do Mont Serra, conhecido como Morro do Caixa. As aulas do estágio ocorreram dentro do "Projeto Travessia", que na época estava sendo executado pelo Centro Cultural. A comunidade onde está localizado o Centro, famosa também por ser a sede da Escola de Samba Embaixada Copa Lord, possui uma população predominantemente de afrodescendentes ${ }^{2}$ oriundos dos

${ }^{2}$ Utilizei este termo, pois o mesmo foi mobilizado no relatório. 
municípios rurais próximos a Florianópolis, segundo as palavras do próprio relatório (MARTINS; SILVA, 2000).

As aulas tiveram como foco central o aprendizado sobre História de Florianópolis por meio das músicas e cantigas de roda da cidade pertencentes ao que os estagiários denominaram de cultura popular. Ao abordar o conceito de cultura popular, apresentam o que seria a cultura local da cidade de Florianópolis, se afastando dos modelos tradicionais que colocam a tradição açoriana como sinônimo da cultura local. No entendimento desses estagiários, a cultura local é formada por elementos próprios e de influências múltiplas, mas, ainda assim, colocam que a população açoriana foi o principal elemento formador que teve que se adaptar à geografia e aos elementos específicos da cidade, inclusive assimilando outras culturas; nessa lógica, o projeto não é uma expressão da cultura açoriana, mas da cultura local que foi constituída por diversas culturas, principalmente indígena e africana.

É verdade que os colonizadores açorianos foram o principal elemento de formação do povo que habita a zona litorânea de Santa Catarina. Mas, também é verdade que este contingente foi obrigado a um árduo processo de adaptação a uma geografia muito diversa da de origem, e só o fez, com a assimilação de complexos inteiros de outras culturas. Portanto, nosso trabalho não se trata de nenhuma "manifestação típica açoriana", mas sim da cultura local que absorveu elementos de outras culturas, 


\section{sobretudo das populações indígenas e de origem africana (MARTINS; SILVA, 2000, p. 12). ${ }^{3}$}

Realço que, mesmo contemplando a parcela da contribuição africana e indígena na constituição da cultura local de Florianópolis, estas ainda aparecem como elementos que irão se unir, aglutinar e incorporar na cultura açoriana. A política de assimilação, termo utilizado pelos estagiários, segundo Mbembe (2001) nada mais é do que des-substancializar e estetizar a diferença, onde os "nativos" são incorporados nesse âmbito da modernidade na medida em que são "convertidos" e "cultivados", isto é, conseguem se encaixar num ideal de cidadania.

Os estagiários se apropriam do entendimento de que diferentes culturas entrecruzadas formularão a cultura local da cidade, que é uma compreensão positiva e uma alternativa criativa à imposição da colonialidade do poder e do racismo que irá desconsiderar as culturas não europeias. No entanto, ainda mantêm em seus usos a cultura açoriana como elemento a ser visto como hegemônico, enquanto as contribuições das populações indígenas e africanas surgem como os elementos secundários a serem assimilados e cooptados. Podemos verificar como a colonialidade do poder, ou em outros termos o racismo, cria uma imposição de classificação da população mundial como a raiz de um padrão de poder que será manuseado em diversas

\footnotetext{
${ }^{3}$ Nos trechos retirados dos relatórios optei por manter a grafia original conforme a escrita dos estagiários e estudantes.
} 
dimensões e escalas (QUIJANO, 2009), inclusive selecionando o que será visto como elemento cultural preponderante, como no caso do elemento açoriano, elevado na narrativa dos estagiários. Portanto, é notável que mesmo com as apropriações e "maneiras de fazer" os estagiários ainda reproduzem a mesma lógica colonialista. O desafio do ensino de História das Áfricas deve atentar para a construção de um conhecimento que reafirme a atuação destas populações para a formação do país, assim como os não africanos e não indígenas. De igual forma, devemos observar que alguns conceitos, quando não aprofundados e problematizados, podem ser apropriados de maneira errônea pelos estudantes, ou ainda de modo a esquecer o real signo deste conceito, como no caso do termo assimilação; por isso se torna fundamental o apontamento do significado desta palavra, a fim de evidenciar aos estudantes todo o processo de colonização, inclusive a sua face violenta.

No relatório intitulado "República em Santa Catarina: modernidade e exclusão - ações e reações que transformaram as estruturas sociais, políticas e econômicas entre o fim do século XIX e início do século XX”, publicado no ano de 2006 e executado na escola IEE, numa turma de primeiro ano do ensino médio, é possível verificar a mesma invisibilização. Nesse estágio, a finalidade das aulas era a percepção das transformações ocorridas em Santa Catarina entre o final do século XIX e o início do XX como parte das mudanças ocorridas com a ascensão da República no Brasil. Neste entremeio, as aulas 
abordaram, em geral, as tensões da sociedade burguesa na modernização, a primeira república em Santa Catarina e os conflitos pertencentes a este período, a imigração e, por fim, as modificações no cenário de Florianópolis com a modernização (DIHEL; GUEDES; PAISNI, 2006).

Em uma das aulas dos estagiários foi abordada a temática da imigração para o Estado de Santa Catarina, objetivando perceber a importância desta para o desenvolvimento econômico e para a diversidade cultural do estado. Segundo o relatório, a intenção era "relacionar o processo migratório no Estado de Santa Catarina e em Florianópolis com o surgimento das novas atividades econômicas urbanas, industriais e agrícolas, ligadas à modernidade ambicionada pela República." (DIHEL; GUEDES; PAISNI, 2006, p. 111). Os estagiários realizaram, inclusive, uma problematização sobre o ideal do progresso advindo com a imigração europeia, e a necessária relativização desse ideal construído a partir de uma História eurocêntrica. Contudo, como lembra Certeau (2003), a apropriação consiste na mobilização própria de referências num dado momento, logo, mesmo se apropriando desta problematização, ainda usam repertórios particulares que reforçam o ideal de progresso trazido pelos europeus nas suas aulas. Em contrapartida, aos negros e índios, populações majoritárias e que atuaram tanto economicamente como culturalmente na construção do Brasil e de Santa Catarina, resta apenas uma citação no corpo do texto. 
Com o intuito de estabelecer uma ligação entre o litoral e os campos de Lages, se deu em 1829 (ainda no Império), a instalação do primeiro grupo de imigrantes alemães na localidade conhecida hoje como São Pedro de Alcântara. Nessas regiões, transformaram também a paisagem cultural, valorizando a ética do trabalho, introduzindo novos padrões alimentares e modificações na língua portuguesa, que ganhou palavras novas e um sotaque particular. Os imigrantes europeus, do Oriente Médio e asiáticos, influenciaram a formação étnica do povo brasileiro, sobretudo na região Centro-sul e Sul do País. Tendo em conta as contribuições de índios e negros, disso resultou uma população etnicamente diversificada, cujos valores e percepções variam de um segmento a outro, no âmbito de uma nacionalidade comum (DIHEL; GUEDES; PAISNI, 2006, p. 113).

Destaco que mesmo quando o foco é abordar a imigração europeia, o racismo, intrínseco nas relações sociais, faz com que a participação dos negros seja silenciada no processo. Os estagiários, mesmo tendo conhecimento do processo de modernização de Florianópolis pautado nos ideais de progressos europeizantes, ao tratar o elemento cultural europeu e as modificações nos costumes do Estado com a chegada destas populações, acabam por se apropriar e reforçar os ideais de modernidade aliado ao europeu e, mesmo que inconscientemente, silenciam a ação das populações de origem africana. Neste mesmo segmento, podemos inferir a branquitude exposta nos 
trechos analisados acima, em que o negro e o indígena aparecem como elementos que apenas contribuíram para a formação do país, mas estes não são colocados como elementos estruturantes, como ocorre com o branco europeu. Ou seja, o branco é o pilar da construção do Brasil, enquanto ao negro e aos indígenas restam algumas pequenas influências, fenômeno este oriundo do racismo que é estruturante da sociedade brasileira.

Stuart Hall (1997), ao abordar o conceito de representação, pontua que cada indivíduo, por meio do uso das coisas, do que pensa ou diz, isto é, da forma como representa tais situações, cria um significado, sendo este estabelecido, portanto, a partir das estruturas de interpretação pessoais. Este significado será constituído a partir do modo como utilizamos tais elementos em nossas práticas. Nesse ponto de vista, os estagiários, ao se apropriarem das concepções do trecho acima, mobilizam os aspectos das populações negras e de origem africana de tal forma que transmitem a representação e o significado, mesmo que não intencional, de que estes só fizeram parte da História do Brasil no período da escravidão, desaparecendo após a abolição desta. Hall (1997) evidencia que a representação por meio da linguagem produz, incessantemente, significados, sendo importante estarmos atentos a quais significados uma pequena frase dentro de um parágrafo complexo pode estar carregando. Nessa perspectiva, a colonialidade do poder e do saber, isto é, o racismo intrínseco em nossa sociedade, se faz presente ao reforçar a percepção de que estas populações só se tornam 
importantes para a historiografia enquanto estas eram objetos e propriedade dos brancos; após a libertação eles são apagados da narrativa histórica.

O Relatório Final de Estágio que tem como título "Imigração e Colonização", publicado em 2001, é referente à experiência de estágio no Colégio de Aplicação, numa turma de $1^{\circ}$ ano do ensino médio. $\mathrm{O}$ objetivo do estágio era abordar a questão da imigração europeia no Brasil a partir do século XIX e suas contribuições para a economia do Sul e do Sudeste, como também para a vida dos próprios alunos. Numa das primeiras aulas foi questionada a problemática dos conceitos de "cultura" e "identidade", como elementos de diferenciação social no Brasil, salientando este como um país que busca uma aparência culturalmente homogênea quando, na verdade, é um bloco de elementos culturais heterogêneos, chamando a atenção dos estudantes para as práticas que nos fazem pertencer a determinados grupos. Nessa perspectiva, o direcionamento do estágio seria a construção de conceitos de identidade e cultura, compreendendo estes num espaço multicultural, utilizando como viés a imigração italiana e alemã do Sul do Brasil.

Respaldado na imigração de italianos e alemães no sul do Brasil a partir do sec. XIX, tinha nestas aulas o objetivo de possibilitar aos alunos construirem os conceitos de "cultura" e "identidade", a fim de que pudessem agir construtivamente em uma 
realidade multicultural (ROSA; KUHNE; FERNANDES, 2001, p. 15, grifo meu).

É evidente a colonialidade do poder e do saber também nesse caso, pois existe um silenciamento e um apagamento da existência das populações africanas, colocadas como questões a serem descartadas, e as concepções de multiculturalismo, cultura e identidade são pautadas nas diferenças apenas entre etnias europeias. Nessa abordagem, é notável como os estagiários formulam táticas de apropriação apontando a importância da noção da realidade multicultural em nosso cotidiano, algo que subverte a sistemática do racismo na sociedade. Apesar disso, estes, ao criarem e inventarem os seus enunciados, confirmam em suas maneiras de fazer os traços que ainda permanecem dessa colonialidade (CERTEAU, 2003). É preciso frisar que a representação destas populações como algo em segundo plano ou sem importância transmite diversos significados e, por meio da nossa linguagem e do modo como representamos, este significado pode vir a se tornar algo natural; isto posto, se torna imprescindível a problematização desta representação, para assim evitarmos a naturalização dessas ideias como algo normal (HALL, 1997).

Estes relatórios se assemelham em alguns aspectos, por exemplo, para além de tratarem da imigração, o seu foco é a imigração europeia, seja ela alemã, italiana ou açoriana. Nos seus enunciados, quando se referiam às contribuições culturais e sócio-históricas trazidas com os imigrantes europeus, as três primeiras narrativas colocavam 
lado a lado as contribuições também dos africanos. Estas, por sua vez, eram expressas em apenas uma frase e nada a mais que isso em todo o relatório. Porém, é importante sublinhar que estes relatórios, ao mencionarem as contribuições de ambas as populações, omitiam a brutal diferença e também a razão existente entre a vinda dos europeus para o Brasil e a vinda forçada dos africanos que foram escravizados. $\mathrm{O}$ que eu quero demonstrar é que se torna implícita nos textos a menção às populações africanas também como imigrantes, como se estas tivessem vindo para o Brasil à procura de melhores condições de vida, assim como os imigrantes europeus, apagando toda a violência por que passaram desde a sua captura em África. É primordial apresentar as contribuições de ambas populações para o Brasil, mas devemos nos ater aos distintos contextos históricos e explicitar os fatores que obrigaram os africanos a virem ao Brasil. Neste sentido, constatei outro problema, que é justamente o africano ou o negro apenas como elemento contribuinte da cultura brasileira, mas não como a principal estrutura de formação desta, fato que nos remete ao lugar de poder estrutural que o branco ocupa, colocando este como o elemento essencial da cultura brasileira. Destaco que essa narrativa, em muitos casos, não é um desejo intencional por parte dos estagiários, mas é resultado da formação de uma estrutura narrativa da história do Brasil que tem o racismo e a branquitude como pilares.

O esquecimento não ocorre somente quando trazemos à tona a temática da imigração, mas também quando saímos da ótica do 
conteúdo e ampliamos as lentes para analisar os conteúdos programáticos elaborados pelos estagiários. No relatório que teve como base o projeto chamado de "À ditadura, aquele abraço", que foi realizado no terceiro ano do Colégio Estadual Anísio Teixeira e publicado no ano de 2005, o objetivo das aulas seria abordar o período da Guerra Fria destacando as suas transformações para além da questão política e abordando, especificamente, a Ditadura Militar no Brasil. Os objetivos específicos do projeto foram:

Identificar em movimentos contestatórios atuais possíveis conexões com o período da ditadura militar brasileira, mostrando assim, a forte repressão sofrida naquele momento; Pensar a mudança do modo de vida da classe média com a entrada de novas tecnologias na vida doméstica; Contextualizar os movimentos contestatórios da juventude, contemplando neste contexto o processo da conquista de uma maior liberdade sexual; Valorizar as lutas femininas por mais direitos e maior liberdade, como também notar as transformações do comportamento feminino em relação aos dias de hoje; Pensar acerca das implicâncias no sentido de rupturas e permanências sobre a queda do Muro de Berlim e o fim do socialismo; Caracterizar o processo de abertura política e reorganização democrática no Brasil (SILVA; TRIDAPALLI; PRADO, 2005, p. 20).

Para chegar a esses objetivos os estagiários aplicaram um questionário no qual era indagado quais seriam os temas, dentro do 
período da Guerra Fria, que mais despertavam o interesse dos alunos. Entre esses temas estavam listados: Chegada do Homem à Lua, Queda do Muro de Berlim, Corrida Armamentista, Movimento Hippie, Golpe de 64, Construção de Brasília, Repressão na Ditadura no Brasil, Guerra do Vietnã, Cuba Socialista, A descolonização da África. $\mathrm{Na}$ análise descrita pelos estagiários os temas de maior interesse dos alunos, com 21\% do total de 17 alunos, foram: Chegada do Homem à Lua, Queda do Muro de Berlim, Corrida Armamentista, Movimento Hippie. Em segundo plano estavam os temas: Golpe de 64, Construção de Brasília, Repressão na Ditadura no Brasil (SILVA; TRIDAPALLI; PRADO, 2005). Os estagiários colocaram em anexo somente dois destes questionários. Em relação a estes, especificamente, a preferência dos temas aparece como descrita pelos estagiários, sendo que o tema descolonização da África foi o que estava na lista como de menor interesse. Na própria análise dos estagiários da lista de preferências dos alunos, a descolonização da África não foi sequer citada, nem para reafirmar a falta de interesse dos alunos por esta temática.

O mesmo esquecimento pode ser notado no relatório intitulado "As experiências da docência: novas perspectivas sobre o ensino de história"; este foi publicado em 2006 e executado no IEE na turma de segundo ano do ensino médio, tendo como tema central das aulas o período da Guerra Fria, enfocando o surgimento das Ditaduras Militares e movimentos de contracultura. Neste relatório é possível perceber resquícios da colonialidade do saber, já que os estagiários dão 
preferência para diversos assuntos e a questão da África surge em segundo plano, como algo complementar. De 18 planos de aula executados pelos estagiários, apenas o último teve como objeto a descolonização da África, sendo que dentro do plano de aula essa temática, na verdade, era só um apêndice, pois a aula era já o fechamento do estágio. Vejamos os objetivos da aula:

Objetivos Gerais: Analisar com os alunos o processo de descolonização e fragmentação do continente africano e suas consequências na nova formação geopolítica da África, bem como, os resultados alcançados com a aplicação do Projeto de Estágio na turma incentivando a inserção destes conhecimentos ao cotidiano dos estudantes.

Objetivos específicos:

- Analisar a descolonização da África e da Ásia.

- Estimular o senso crítico dos alunos acerca dos temas contemplados através deste Projeto de Estágio.

- Estabelecer relações entre os conteúdos abordados no referido Projeto com o cotidiano dos alunos.

- Avaliar através das análises dos estagiários e dos alunos os resultados alcançados com a execução do tema proposto pelo Projeto de Estágio (SILVEIRA; PLEGER; PAVANELLO, 2006, p. 126, grifo meu).

Diante disso, fica a questão: qual o motivo deste desinteresse e esquecimento notado nos relatórios acima? Seria o racismo que é constantemente reproduzido por meio do silenciamento e desconhecimento em relação às Áfricas? Conforme Mignolo (2003) e também as contribuições de Fanon (2005) aqui já citadas, o colonialismo e o eurocentrismo andam juntos, sendo este último a raiz reprodutiva da colonialidade do saber, que controla o conhecimento e a subjetividade; por consequência, as histórias e saberes locais oriundos 
da Europa são concebidos como projetos globais, colocando o continente como ponto de referência. Fanon (2005) nos alerta que é o colono ou o europeu que escreve a história; esta história não é a história do local que foi saqueado pela ação europeia, mas é a história da sua nação neste território, ou seja, é o prolongamento da história da sua metrópole, no caso a Europa. Nesse aspecto, a experiência de outros continentes, como a África, é negada, esquecida e até mesmo vista como "não sendo tão importante", repercutindo num desconhecimento e também falta de interesse, que não deixa de ser resultado da permanência do racismo epistemológico ou, de modo mais amplo, da colonialidade do saber na atualidade.

No relatório já comentado, intitulado "República em Santa Catarina: modernidade e exclusão - ações e reações que transformaram as estruturas sociais, políticas e econômicas entre o fim do século XIX e início do século XX”, também é notável este fenômeno. Num questionário aplicado com os alunos no início do estágio, uma das questões indagava sobre qual seria o período da História que os alunos mais gostavam de estudar ou gostariam de estudar. Entre as respostas de quinze alunos apenas uma fazia alusão a um elemento das Áfricas, com a presença do Egito na resposta. "Sim. O Egito. Sempre me interessei por mistérios e artefatos antigos" (DIHEL; GUEDES; PASINI, 2006, p. 66). As outras respostas giravam em torno de História Moderna, descobrimento do Brasil e História Contemporânea. O Egito que desperta interesse nos estudantes é aquele Egito antigo, com faraós, 
pirâmides, um Egito encapsulado no passado e encerrado nas suas origens. A partir de Antonacci (2013) verificamos que essa concepção é oriunda, ainda, das classificações excludentes feitas na obra Filosofia da História, de Hegel, em 1831, na qual, separando o histórico do préhistórico, atribui à África a porção sem história do mundo. Para este, o continente africano não possui história, nem movimentos ou progressos, era um espaço congelado no tempo, logo, para ele, o que vemos em África na atualidade é a mesma coisa vista no passado, ou seja, a representação da África presa a um imobilismo histórico.

Quando aprendemos sobre a Europa verificamos a relação desta na História do Brasil e de outros locais, seja culturalmente, como politicamente ou economicamente; igualmente a História das Áfricas não é centrada somente no continente africano, esta é interconectada com a História de outros continentes e países, inclusive a Europa. Em sua tese de doutoramento, Anderson Oliva (2007) chama atenção para a necessidade de levarmos em consideração, quando falamos em História das Áfricas, tanto o contexto do universo africano como também suas relações exógenas e endógenas, como as relações formadas no âmbito do mundo atlântico que influenciou diretamente as vivências, experiências e leituras sobre o mundo tanto em África como fora dela. Desse modo, como falar da supremacia europeia sem citar a inferiorização do continente africano? Dois imaginários criados juntos e simultaneamente. Os africanos foram trazidos à força para o Brasil, estes também construíram a História do nosso país, portanto, quando 
falo da História dos africanos e afro-brasileiros este contexto também está integrado.

Neste artigo foi possível verificar os diversos modos como, mesmo sutilmente e quase imperceptível, a História das Áfricas é esquecida, silenciada ou diminuída no contexto escolar. É percebida, num primeiro momento, a representação da ausência desta imagem da África, quando não é nomeada, citada ou referenciada nos diferentes conteúdos de História ou ainda aparece em menor exposição, quando comparada com outros conteúdos. Por que esquecemos com tanta facilidade da África? Por que ela não aparece nos conteúdos programáticos? Num segundo momento, aparece nas aulas dos estagiários a referência a populações negras na História, mas ainda assim aparecem em segundo plano ou após uma longa explanação sobre colonização europeia, sendo expressas por apenas uma palavra ou citação, ou seja, permanece a representação destas como uma menor relevância na História. Os estagiários, ao tratar da colonização e construção sócio-histórica do Brasil ou de Santa Catarina, pontuam a participação ativa dos agentes advindos da Europa. Em contrapartida, os elementos oriundos das populações negras são considerados como a parcela que apenas contribuiu para tal construção, mas não como elementos estruturais, como são mencionados os migrantes brancos, evidenciando assim a atuação da branquitude nestes relatórios. Ressalto que esta articulação discursiva não é algo original destes relatórios, mas é a herança de uma representação que foi cristalizada ao longo do 
tempo, a partir do momento em que se desejava branquear a imagem da população brasileira. Nesse sentido, a população negra é citada ao lado dos imigrantes europeus ao falar da sua contribuição cultural ao Brasil, mas não é mencionada a diferença no modo como estes chegaram ao nosso país. Num terceiro momento, é notável a representação destes como indivíduos sem ação, desumanizados e sem agência histórica, delegando ao europeu a capacidade de contar a História dos Africanos. Isto pode ser observado desde o trecho em que a descolonização da África se torna resultado apenas da ação dos europeus, ou quando os negros são culpados pelo racismo na atualidade, como se estes não fossem conscientes do que ocorre e não fossem capazes de escolher entre aceitar a sua cultura ou não, assim como todos os seres humanos podem.

Em suma, foi evidenciado neste artigo que a História das Áfricas e a História da população negra, quando não está ausente, seja pelo desinteresse dos estudantes em estudos sobre a temática ou pela falta de preparo dos estagiários, surge a partir do seu significado para a escravidão, isto é, os estagiários a compreendem a partir da sua vinculação com o regime escravista no Brasil. No que diz respeito à valorização dos negros e do seu papel como agentes históricos na construção do Brasil, demanda reivindicada ao longo do tempo pelos movimentos sociais e que também emerge na LDB, os relatórios analisados exprimem a branquitude presente em nossas relações, ao colocarem a atuação do negro em menor escala em relação aos brancos. 
De mesmo modo, foi observado na abordagem direcionada à disciplina de História o uso de categorias sustentadas pela epistemologia eurocêntrica, sem devida reflexão, o que corrobora com o olhar opressor à história dos negros, preponderante na atualidade. Ou ainda, verificando o uso de categorias que restringem estas populações como seres essencializados e próximos do não ser, como o termo escravo ${ }^{4}$.

\section{Referências}

APPIAH, Kwame Anthony. Na casa de meu pai. Rio de Janeiro: Contraponto, 1997.

BÂ, Amadou Hampaté-Bâ. A tradição viva. In: KI-ZERBO, J. (Coord.). História Geral da África. I. Metodologia e Pré-História da África. 2010.

BHABHA, Homi K. O compromisso com a teoria. In: O local da cultura. Belo Horizonte: Editora da UFMG, 1998.

CARDOSO, Paulino de Jesus Francisco. Negros em Desterro: experiências de populações de origem africana em Florianópolis, 18601888. Tese (Doutorado em História) - Programa de Pós-graduação em História, Pontifícia Universidade Católica, São Paulo, 2004.

CERRI, Luis Fernando. Os conceitos de consciência histórica e os desafios da didática da história. Revista de História Regional, v. 6, n. 2, p. 93-112, 2001.

CERTEAU, Michel de. A invenção do cotidiano: artes de fazer. Trad. de Ephraim Ferreira Alves. Petrópolis: Vozes, 2003.

${ }^{4} \mathrm{Na}$ dissertação completa, tenho como objetivo analisar os Relatórios de 2007 até 2015 e, dessa forma, averiguar se a Lei Federal 10.639/03 incidiu de alguma maneira nas aulas dos estagiários e nas representações dos estudantes, identificando as mudanças em relação a estes relatórios analisados até 2006. 
DIEHL, Alecsandro; GUEDES, Claudete Maria; PASINI, Janete Maria. República em Santa Catarina: modernidade e exclusão - ações e reações que transformaram as estruturas sociais, políticas e econômicas entre o fim do século XIX e início do século XX. Relatório de Estágio Supervisionado. UDESC, 2006.

FANON, Frantz. Sobre a violência. In: Os Condenados da Terra. $1^{\text {a }}$ reimpressão. Juiz de Fora: Ed. UFJF, 2005.

FANON, Frantz. Pele negra máscaras brancas. Tradução de Renato da Silveira e Prefácio de Lewis R. Gordon. Salvador: Editora da UFBA, 2008.

FONSECA, Selva G. Didática e prática de ensino em História. Campinas: Papirus, 2007.

GOODSON, Ivor F. Currículo - teoria e história. Petrópolis: Vozes, 1995.

HALL, Stuart. Da diáspora: identidades e mediações. Belo Horizonte: Editora UFMG, 2003.

HASENBALG, Carlos A. Discriminação e desigualdades sociais no Brasil. Rio de Janeiro: Graal, 1979.

HOUNTONDJU, Paulin J. Conhecimento de África, conhecimentos de africanos: duas perspectivas sobre

os estudos africanos. In: SANTOS, Boaventura de Sousa; MENESES, Maria Paula (Org.). Epistemologias do Sul. Coimbra: Edições Almedina, 2009. p. 73-118.

JORGE, Mateus Perez; SCHWEDER, Maro; MACEDO, Fábio. A guerra fria e a ditadura militar no Brasil: Em busca de uma história em movimento. Relatório de Estágio Supervisionado. UDESC, 2006. 
LANDRA, Elisangela da Silva; SPCART, Joel; RADA NETO, José. A revolução industrial e a inserção de Florianópolis na modernidade. Relatório de Estágio Supervisionado. UDESC, 2005.

LEITE, Ilka Boaventura. Descendentes de Africano em Santa Catarina: Invisibilidade Histórica e Segregação. In: LEITE, Ilka Boaventura (Org.). Negros no Sul do Brasil. Ilha de Santa Catarina: Letras Contemporâneas, 1996. p. 38-41.

LIPPOLD, Walter Günther Rodrigues. A África no Curso de Licenciatura em História da Universidade Federal do Rio Grande do Sul: possibilidades de efetivação da Lei 11.645/2008 e da Lei 10.639/2003: um estudo de caso.166f. Dissertação (Mestrado em Educação) - UFRGS, Porto Alegre, 2008.

LUCIANO JUNIOR, Ademir Soares; SILVA, Cintia Ertel. Escravos, alemães, subversivos na Ditadura e moradores de favela durante os séculos XIX e XX da história do Brasil e de Santa Catarina. Relatório de Estágio Supervisionado. UDESC, 2006.

MARTINS, Alexandre; SILVA, Haroldo Silis Mender. A música: cantigas e histórias da ilha. Relatório de Estágio Supervisionado. UDESC, 2000.

MBEMBE, Achille. Crítica da razão negra. Antígona, 2014.

MIGNOLO, Walter D. Histórias locais/Projetos globais: colonialidade, saberes subalternos e pensamento liminar. Belo Horizonte: UFMG, 2003.

OLIVA, Anderson. Lições sobre a África: Diálogos entre as representações dos africanos no imaginário ocidental e o ensino da história da África no Mundo Atlântico (1990-2005). 404f. Tese de Doutorado - UNB, Brasília, 2007.

OLIVEIRA, Luiz Fernandes de. Histórias da África e dos africanos na escola. As perspectivas para a formação dos professores de História 
quando a diferença se torna obrigatoriedade curricular. 281p. Tese de Doutorado - PUC-RJ, Rio de Janeiro, 2010.

POLUCENO, Evilasia; MARTINO, Marlen Batista de; LAZZARIS, Milana Cristina. Relatório de Estágio. Relatório de Estágio Supervisionado. UDESC, 2001.

QUIJANO, Anibal. Colonialidade do poder e classificação social. In: SANTOS, Boaventura de Sousa; MENESES, Maria Paula (Org.). Epistemologias do Sul. Coimbra: Edições Almedina, 2009, p. 73-118.

ROSA, Cesar Cancian Dalla; KUHNE, Mário Ernesto; FERNANDES, Leda Maria. Imigração e colonização. Relatório de Estágio Supervisionado. UDESC, 2001.

SILVA, Ana Carolina Wessler Prudencio; TRIDAPALLI, Ana Laura; PRADO, Roberto Oliveira do. À ditadura, aquele abraço. Relatório de Estágio Supervisionado. UDESC, 2005.

SILVA, Marcia Claudio Cardoso; TEDESCO, Marcos Anderson; SAYAO, Thiago Juliano. Violência hoje e suas raízes sociais no período colonial. Relatório de Estágio Supervisionado. UDESC, 2001.

SILVA, Cristiani Bereta da. Formação histórica e narrativas: efeitos de sentido sobre o ensino de história e o espaço escolar no estágio supervisionado. In: ROCHA, Helenice; MAGALHÃES, Marcelo; GONTIJO, Rebeca (Org.). O ensino de história em questão: Cultura histórica, usos do passado. Rio de Janeiro: FGV, 2015, p. 163-182.

SILVEIRA, Israel da; PLEGER, Kelwyn; PAVANELLO, Sávio Lopes. As experiências da docência: novas perspectivas sobre o ensino de história. Relatório de Estágio Supervisionado. UDESC, 2006.

WALLERSTEIN, Immanuel. Análisis de sistemas-mundo: Una introdución. México: Siglo Veinteuno, 2011. 
Recebido em 03/05/2017, aceito para publicação em 22/07/2017

Revista Vernáculo n. ${ }^{\circ} 40$ - segundo semestre /2017

ISSN 2317-4021 